the beautiful $M$. grandiflora. He has been at considerable pains to examine for himself the curious changes undergone by the ovule in maturation, publishing an account of it in "Comptes Rendus," 1xvi. 700, apparently ignorant of Prof. Asa Gray's exceedingly clear and detailed account of the same, given twelve years ago in the Journal of the Linnean Society, ii. 106. The old genera Talazma, Manglietia, and Michelia are all sunk in Magnolia, which genus, with Liriodendron, constitutes the series Magnolieæ. The three former genera are very briefly disposed of, and whether specimens of each have been examined, is by no means clear. After describing successively the structural features of each Series, $M$. Baillon gives us a short historical summary of the Natural Order, then he discusses the points in which all, or nearly all, of the genera agree. The only three absolutely constant characters are: the woody stem, the alternate leaves, and the presence of albumen in the seeds. A triad, equally constant, we may remark, in many other Natural Orders, just as flour, suet and salt, may be common to every different sort of pudding. Eight characters are generally prevalent, the exceptions being few or solitary; these refer to the form of the receptacle, concave only in two genera, which same pair are the only exceptions to the otherwise constantly double perianth ; polypetaly ; direction of the micropyle of the ovule; apocarpy and placentation; stipulation. These we might speak of as the currants, and peel, and spices, and brandy, and what not, which, judiciously blended with the constituents afore-named, give special character and pre-eminence to plum-pudding. Technical diagnoses of the five Series follow. Then we have the histology of the wood and bark; a discussion of the affinities of the order; a paragraph on its geographical distribution; an account of the properties and uses of various species; and lastly, technical descriptions in Latin, of each genus, as maintained by M. Baillon. These technical descriptions, if given at all, should be accompanied by a distinct generic synonymy. It is too much to expect every one to turn back to pages so and so, and unravel it for himself, where the mention of it may read as merely incidental.

D. OLIVER

\section{FICK ON THE TRANSFORMATION OF FORCE}

Die Naturkrafte in ihrer Wechselbezichung. By Adolf Fick. (Würzburg, 1869. London: Williams and Norgate.)

PROFESSOR FICK, who has recently been moved from Zurich to Würzburg to fill the chair of Physiology there, vacant through the untimely death of Von Bezold, is well known not only to physiologists by his many excellent researches, but also to a far wider circle through the now well-known experiments on muscular physics carried out by himself and Wislicenus. In these six popular lectures he attempts to carry an intelligent and attentive audience, not possessing special scientific knowledge, swiftly through the great story of the transformation of force, showing them, in a quiet, lucid way, how the parts are played on those two great stages, the macrocosm of the universe and the microcosm of the human body.

The first four lectures are given up entirely to the consideration of the correlation of purely physical forces.
Starting from simple facts about heat, the author works his way through heat as a mode of motion, through concrete conceptions of molecular movements in changing bodies, to the general doctrine of the transformation of force and the numerical relations between one force and another.

In his fifth lecture, treading upon his own ground, he shows that the microcosm is but a stage where forces shift and change; and that no exact researches have at present in any way shown the necessity of believing that in the living body there exists any new force besides those at work in the world around. $\mathrm{He}$ is careful to point out that no thoroughly satisfactory balance sheet of the forces that come to and go out from a living body has yet been shown, so difficult is the task; but, though the details have yet to come, the general principle gains daily confirmation. Human force is but a transformation of chemical force, and main steals oxygen to do his work. Plants unburn what the animal burns; and so the heat of the sun brings back oxygen to the world.

And this leads the lecturer in his last lecture to the question, How does the sun get his heat? After quoting and discussing Mayer's hypothesis of the feeding of the sun with meteors, and pointing out the next question, "Whence comes the force which drives the meteors?" he finishes by dwelling on Clausius' theory of the constant loss of force in the shape of heat that cannot be weaned back to any other mode of motion, and on the general conclusions that may be drawn from it. These we prefer to give in his own words :-

If, then, when mechanical force passes into heat, some of that heat can never be brought back to be mechanical force, and if the change from mechanical force to heat be ever going on, all the force in the universe must at last take on the form of heat. But if that be so, then at last all differences of temperatures must disappear, and everything end in a universal Death. The whole chain of Cosmic events must therefore be looked upon not as formed of cycles, so that, cycle sweeping round upon cycle, the universe stands for ever the same, but as being a process of Evolution striving towards an End.

We are come to this alternative: either in our highest, our most general, our most funclamental scientific abstractions, some great point has been overlooked; or the universe will have an end and must have had a beginning; could not have existed from Eternity, but must at some date not infinitely distant have arisen from something not forming part of the chain of natural causes, i. e. must have been created.

\section{FOSTER}

\section{OUR BOOK SHELF}

Theoretical and Applied Mechanics, for Schools, Colle'ges, Candidates for University Examinations, \&oc. By R. Wormell, M.A., B.Sc. (London: Groombridge and Sons.)

WE are glad to see London University graduates recruiting the ranks of educational writers. Mr. Wormell states in clear and concise language the principles of elementary Statics and Dynamics, in close accordance with the syllabus of requirements for passing the examinations for the B.A. and B.Sc. degree at the London University. $\mathrm{He}$ gives hardly more nor less than this, but avoids at the same time an error into which most of our writers on the subject fall, viz. the overcrowding of their books with problems, which the purely didactic portion of the book does not enable even the gifted student to solve. Mr. Wormell adds to his test a great variety of really instructive solved problems, which will go far to help the student in finding the solutions of those given with the numerical answers 